\title{
Simultaneous extraction and fractionation of lipids from the microalga Nannochloropsis sp. for the production of EPA-rich polar lipid concentrates
}

\author{
María J. Jiménez Callejón ${ }^{1}$ • Alfonso Robles Medina ${ }^{1}$ (D) • Pedro A. González Moreno ${ }^{1}$ - Luis Esteban Cerdán ${ }^{1}$. \\ Sandra Orta Guillén ${ }^{1}$ • Emilio Molina Grima ${ }^{1}$
}

Received: 18 September 2019 /Revised and accepted: 3 January 2020 /Published online: 18 January 2020

(C) The Author(s) 2020

\begin{abstract}
There is broad scientific evidence on the health benefits of omega-3 polyunsaturated fatty acids (n-3 PUFAs), especially docosahexaenoic acid (DHA, 22:6n3) and eicosapentaenoic acid (EPA, 20:5n3). On the other hand, polar lipids (phospholipids, PLs, and glycolipids, GLs) are excellent emulsifying agents, making them useful both as food products and as excipients for drugs and cosmetics. The bioavailability of n-3 PUFAs in the form of PLs is greater than that of ethyl esters and triacylglycerols. This work has developed an easy method for the simultaneous extraction and fractionation of saponifiable lipids (SLs) from the microalga Nannochloropsis sp., using low-toxicity solvents. Firstly, a lipidic fraction very rich in neutral saponifiable lipids (NSLs) was obtained using hexane. Next, an EPA and polar lipids (PLs and GLs)-enriched fraction was obtained using ethanol (96\%). Under optimal conditions, in the first extraction with hexane, an SL extract with $86.3 \%$ NSLs was obtained; this extract contained $88.9 \%$ of the biomass NSLs. Subsequently, in the second extraction step with ethanol (96\%), an SL extract with $87.1 \%$ polar lipids and up to $35.2 \%$ EPA was obtained. This SL extract contained $87.1 \%$ of the polar lipids and $74.7 \%$ of the EPA from the Nannochloropsis sp. biomass.
\end{abstract}

Keywords Extraction · Microalga $\cdot$ Phospholipid $\cdot$ Glycolipid $\cdot$ Polar lipid $\cdot$ Eicosapentaenoic acid (EPA)

\section{Introduction}

There is broad scientific evidence on the health benefits of omega-3 polyunsaturated fatty acids (n-3 PUFAs), especially docosahexaenoic acid (DHA, 22:6n3) and eicosapentaenoic acid (EPA, 20:5n3) (Swanson et al. 2012). These benefits include their ability to reduce cardiovascular problems (Lee et al. 2009), decrease triglyceride levels, and increase HDL cholesterol ("good cholesterol") as well as being antiinflammatory agents (Calder 2012). Whether n-3 PUFAs are used as ingredient in foods, drugs or cosmetics, or as a product in themselves (a nutritional supplement), it is desirable for them to be in the form of concentrates. Therefore, it is convenient to start with raw materials that have a high n-3 PUFA concentration, such as fish oils, krill, and microalgae.

Alfonso Robles Medina arobles@ual.es

1 Department of Chemical Engineering, University of Almería, 04120 Almeria, Spain
Polar lipids (phospholipids, PLs, and glycolipids, GLs), on the other hand, are excellent emulsifying agents, making them useful both as food products and as excipients for drugs and cosmetics. PLs are used in pharmaceuticals and cosmetics as emulsifying agents, humectants, and liposome constituents (van Hoogevest and Wendel 2014). Several studies also suggest that n-3 PUFAs are more protected against oxidation when they are part of PLs (Burri et al. 2012). In addition, the bioavailability of n-3 PUFAs in the form of PLs is greater than that of ethyl esters and triacylglycerols (TAGs) (Rossmeisl et al. 2012; Tang et al. 2012). In this sense, it appears that the n-3 PUFAs in krill oil are better absorbed than those from fish oils because, in the former, a significant portion of the PUFAs are in the form of polar lipids, especially PLs (34-58\% of the total lipids) (Ghasemifard et al. 2014; Burri and Johnsen 2015) and these have emulsifying properties (Mun et al. 2007). Conversely, in a study comparing EPA and DHA absorption from an intake of krill oil and an oil rich in polar lipids from the microalga Nannochloropsis oculata (Kagan et al. 2013, 2015), it was observed that microalgal PUFAs were absorbed at a higher rate than the PUFAs from krill oil. Following this, in a similar study using the same oils 
in rats, Kagan et al. (2015) observed that n-3 PUFAs are absorbed better in the form of GLs than as PLs; perhaps because GLs form smaller micelles than those of PLs during digestive hydrolysis. The GLs rich in n-3 PUFAs have been studied less but there are studies where some of these compounds of microalgal origin show antitumor, antimicrobial, and anti-inflammatory activity (Da Costa et al. 2016).

The best raw materials for obtaining n-3 PUFA concentrates are certain fish oils, krill oil, and marine microalgae. Currently, the main source of n-3 PUFA concentrates are fish oils (Finco et al. 2017) but the overexploitation of fishery resources and the growing demand for these oils has led to a search for new, more sustainable, and safe sources (AdarmeVega et al. 2014). Krill oil is an alternative source of $n-3$ PUFAs that is gaining market share. Its production is based on the fishing of the small crustacean Euphausia superba, which lives in Antarctic waters (Burri and Johnsen 2015), but its overexploitation might be causing serious damage to polar ecosystems as it is a fundamental link in the food chain (Pottel et al. 2014). Its most notable difference to fish oils is that a large portion of the n-3 PUFAs is found as part of PLs (34-58\% of the total lipids) with the rest of its lipid composition being mainly TAGs (23-36\%) (Ghasemifard et al. 2014). As a source of n-3 PUFAs, microalgae have the advantages of being cultivatable under controlled conditions, maintaining a constant biochemical composition and eliminating contaminants; they present greater photosynthetic efficiency, biomass productivity, and growth rates than most oleaginous crops (Chisti 2007); moreover, microalgal lipids have higher EPA or DHA concentrations than fish oils and higher antioxidant lipid contents (like those of carotenoids). Obtaining n-3 PUFAs from photoautotrophic microalgae, such as Nannochloropsis gaditana, Phaeodactylum tricornutum, or Chlorella marina (species with high EPA contents), will be more sustainable than a culture that is heterotrophic since, in the former, the raw materials are mainly sunlight and $\mathrm{CO}_{2}$. Marine microalgae cultivated in continuous mode photobioreactors, employing high dilution rates (between 0.2 and $0.3 \mathrm{day}^{-1}$ ), present high percentages of polar lipids (structural lipids, primary metabolites associated with growth); these are polar lipids (PLs and GLs) that are particularly rich in n-3 PUFAs (EPA and DHA) (Molina et al. 1999). The microalga Nannochloropsis sp. is one of the few species currently accepted as food and it is of particular interest for the production of high-value oil containing n-3 fatty acids, specifically EPA (Chua and Schenk 2017).

Although great interest exists in obtaining EPA and DHA concentrates from microalgae, there is still no standardized method for the large-scale extraction of lipids; this is due to the great heterogeneity of microalgal lipids (for example, they present different lipid class percentages according to the culture conditions) and the morphological variety, especially in relation to their cell wall permeability (Servaes et al. 2015).
Low-toxicity solvents must be used that are allowed in the manufacture of food products, such as hexane/methanol, hexane/ethanol, hexane/isopropanol, and cyclohexane/1-butanol, although these mixtures are better at extracting neutral lipids than polar ones (Ryckebosch et al. 2014b; Servaes et al. 2015). The fractionation of the total SLs into these lipidic species has been performed by scaling up the column fractionation method used at the analytical level but the procedure involves huge solvent consumption; this method uses stationary phases based on silica gel and it sequentially elutes neutral lipids (NLs) with chloroform, GLs with acetone, and PLs with methanol (Ryckebosch et al. 2012). For the scaled-up methods, stationary phases were used such as silica or modified silica and DEAE-cellulose (diethyl amino ethyl cellulose) while organic solvents of different polarities were used as the mobile phases (Christie 2003; Devos et al. 2006; Yoshitomi et al. 2011; Antonopoulos et al. 2013).

To the best of our knowledge, there are no works focused on the specific extraction of polar lipids from microalgae biomass. Some authors, such as Ryckebosch et al. (2014a, b) and Servaes et al. (2015) studied the influence of the extraction solvent (hexane, acetone, ethyl acetate, ethanol, etc.) and the extraction method (Soxhlet, pressurized liquids, and supercritical extraction) on the extractability of the different lipidic classes (NLs, GLs, and PLs). These authors concluded that low polarity solvents are best for the extraction of NLs while the lipids from chloroplasts and membranes, which contain GLs and PLs, respectively, are more effectively extracted using more polar solvents, such as ethanol or methanol. However, direct extraction from the microalgal biomass using polar solvents involves the joint extraction of NLs and polar lipids (Ryckebosch et al. 2014b; Servaes et al. 2015, Jiménez et al. 2020,). Thus, the aim of this work was to obtain EPArich polar lipids through the sequential extraction of saponifiable lipids from Nannochloropsis sp. biomass using lowtoxicity solvents by (i) extraction of NSLs from the original biomass using hexane and (ii) extraction of EPA-rich polar lipids from the previous residual biomass using ethanol.

\section{Materials and methods}

\section{Microalgae and chemicals}

The microalga Nannochloropsis sp. was purchased in a lyophilized state from Monzón Biotech S.L. (Huesca, Spain). It was chosen for its EPA-rich lipid fraction. The complete lipid composition is described in section "Lipidic composition of the microalgal biomass".

The solvents used were ethanol $(96 \% \mathrm{v} / v)$, hexane $(95 \%$ purity), acetone, methanol, and chloroform, all of analytical grade from Panreac AppliChem S.A. (Spain). Nonadecanoic acid (19:0) was used as the internal standard in the analysis of 
fatty acids by gas chromatography (GC) (Fluka Analytical, Sigma-Aldrich, USA) and acetyl chloride as the catalyst in the prior methylation (Fluka Analytical). Hydrochloric acid (37\%, analytical grade) and magnesium chloride 6-hydrate (both from Panreac AppliChem S.A) were used for the determination of total lipids. Finally, silica gel cartridges (Sep-pack plus WAT020520, Waters Corporation, USA) were used for the SL fractionation.

\section{Sequential lipid extraction from microalgal biomass}

To produce EPA-rich polar lipid concentrates, a step-by-step extraction was developed. Firstly, hexane was used to try to specifically remove the neutral lipids from the original biomass. Next, ethanol $(96 \% v / v)$ was used to extract an EPA and polar lipid-enriched fraction from the residual biomass. Figure 1 shows the laboratory-scale lipid extraction procedure. The first extraction step was carried out treating $2.5 \mathrm{~g}$ of dry biomass with different amounts of hexane-the solvent/biomass ratios tested were $5,10,20$, and $30 \mathrm{~mL}$ hexane $\mathrm{g}^{-1}$ dry biomass (db). Extractions were carried out at 20, 40 , or $60{ }^{\circ} \mathrm{C}$ in bottles with screw caps, placed on a water submersible magnetic stirrer (Variomag maxi, Thermo Fisher Scientific, Germany). The extraction mixture was agitated at $300 \mathrm{rpm}$ for time periods between 1 and $20 \mathrm{~h}$. After the extraction, the mixture obtained was filtered (Pobel glass plate, porosity 4, Madrid, Spain) and the hexanic extract collected and fitted to a known volume $(100 \mathrm{~mL})$. Residual biomass was then recovered and used in the second extraction step with ethanol (96\%). Different amounts of ethanol (5$30 \mathrm{~mL} \mathrm{~g}^{-1}$ original $\left.\mathrm{db}\right)$ and temperatures $\left(20-60^{\circ} \mathrm{C}\right)$ were also tested in bottles with screw caps, placed on a water submersible magnetic plate agitated at $300 \mathrm{rpm}$ for $20 \mathrm{~h}$. Finally, the mixture obtained was filtered (Pobel glass plate, porosity 4 ,
Spain) and the ethanolic extract collected and fitted to a known volume $(100 \mathrm{~mL})$. Both hexanic and ethanolic extracts were characterized by determining the parameters described in section Analytical methods.

The scaling up of the extraction process was carried out in 2-L glass reactors, equipped with 4 baffles, jacketed for temperature control, and agitated at $400 \mathrm{rpm}$ with a propeller stirrer (Eurostar digital, IKA, Germany). In these experiments, $50 \mathrm{~g}$ of lyophilized biomass from Nannochloropsis sp. was extracted using $0.5 \mathrm{~L}$ of hexane and ethanol (96\%) in the first and second extraction step, respectively.

The maximal SL yield in the extraction with hexane was measured by Soxhlet extraction. To do this, $2.5 \mathrm{~g}$ of dry biomass was weighed into a cellulose cartridge and placed in a Soxhlet device. Microalgal lipids were extracted for $8 \mathrm{~h}$ using $300 \mathrm{~mL}$ of hexane (12 reflows per hour).

To compare the previous extractions carried out on the dry biomass, the extraction-fractionation procedure was also applied to wet biomass. In this case, certain tests were carried out using wet biomass with an $86 \mathrm{wt} \%$ water content ( $2.5 \mathrm{~g}$ of lyophilized biomass was resuspended in $15.35 \mathrm{~mL}$ of water). The extraction steps were carried out at $40^{\circ} \mathrm{C}$ for $20 \mathrm{~h}$ using $10 \mathrm{~mL}$ of solvent per $\mathrm{g}$ equivalent of dry biomass.

\section{Analytical methods}

\section{Determination of the total lipid, saponifiable lipid, and fatty acid composition}

Total lipids (TLs) include both saponifiable lipids (SLs, lipids containing fatty acids) and non-saponifiable lipids. SLs comprise neutral saponifiable lipids (NSLs, such as acylglycerols and free fatty acids) and polar lipids (such as glycolipids and phospholipids, GLs and PLs). The TL content of microalgal
Fig. 1 Scheme of the simultaneous extraction and fractionation of microalgal lipids from Nannochloropsis sp. lyophilized biomass in two steps using hexane and ethanol $(96 \%$ $v / v)$

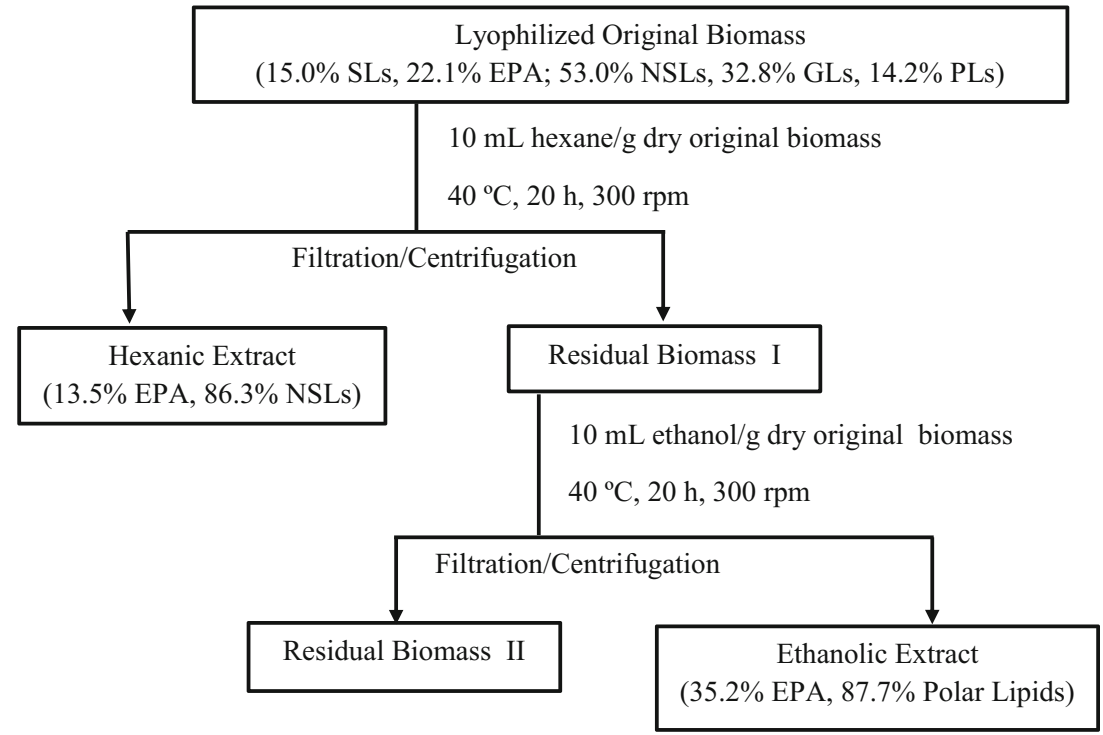


biomass was determined using the method described by Kochet (1978), which is based on the extraction of lipids from lyophilized biomass with chloroform/methanol $(1: 1 \mathrm{v} / \mathrm{v})$.

To determine the SL content of the biomass samples, lyophilized algal biomass (three 10-mg samples of each algal batch) was directly transesterified in $1 \mathrm{~mL}$ of hexane and $0.125 \mathrm{mg}$ of internal standard (nonadecaenoic acid, 19:0), using $1 \mathrm{~mL}$ of a 1:20 v/v solution of acetyl chloride in methanol. The reactions were conducted in tubes heated to $105{ }^{\circ} \mathrm{C}$ for $20 \mathrm{~min}$ for transmethylation. Next, the mixture was cooled to room temperature and $1 \mathrm{~mL}$ of water was added. The tubes were then agitated and centrifuged. Two phases were formed, the upper one (hexane) containing the FAMEs obtained from the SLs present in the microalgal biomass. These FAMEs were analyzed by gas chromatography (GC). This analysis was carried out in an Agilent Technologies 6890N chromatograph (USA), equipped with a capillary column of fused silica OmegaWax $(0.25 \mathrm{~mm} \times 30 \mathrm{~m}, 0.25 \mu \mathrm{m}$ standard film, Supelco, USA) and a flame ionization detector (FID). Nitrogen was the carrier gas at a flow rate of $58.1 \mathrm{~mL} \mathrm{~min}{ }^{-1}$ and a split ratio of 1:40. The injector and detector temperatures were set at 250 and $260{ }^{\circ} \mathrm{C}$, respectively. The oven temperature was initially set at $150{ }^{\circ} \mathrm{C}$ for $3 \mathrm{~min}$, then programmed to increase to $240{ }^{\circ} \mathrm{C}$ at a rate of $7.5^{\circ} \mathrm{C} \mathrm{min}-1$ and set at $240{ }^{\circ} \mathrm{C}$ for $12 \mathrm{~min}$. This analysis gave the SL content per unit mass of dry biomass and the fatty acid composition of microalgal SLs. The fatty acid composition of the SLs was determined by comparing the retention times to those of the PUFA-3 Menhaden oil standard (Supelco) analyzed under the same conditions (Jiménez Callejón et al. 2014).

In addition, the amounts of extracted SLs and their fatty acid profiles in each extraction step were determined by methylation and $\mathrm{GC}$ analysis of the samples. In the case of the hexanic extracts, $0.5 \mathrm{~mL}$ of lipid extract was taken and mixed with another $0.5 \mathrm{~mL}$ of hexane before sample methylation. With ethanolic extracts, $0.5 \mathrm{~mL}$ of sample was firstly dried under a nitrogen stream and then mixed with $1 \mathrm{~mL}$ of hexane.

The SL yield (wt\%), both in hexanic and ethanolic extracts, is defined as the percentage of extracted SLs with respect to the total amount of the SLs contained in the original biomass (Eq. 1). Similarly, the NSL, GL, and PL yields (wt \%) are defined as the percentage of each of the lipid types recovered with respect to the total content of that lipid type in the original biomass (Eq. 2).

SL yield $(\mathrm{wt} \%)=\frac{(100 \times \text { SLs recovered })}{\text { SLs contained in the original biomass }}$

NSL, GL or PL yield (wt\%)

$$
=\frac{(100 \times \text { NSLs, GLs or PLs recovered })}{\text { NSLs, GLs or PLs contained in the original biomass }}
$$

Similarly, the EPA yield (wt\%), both in the hexanic and ethanolic extract, is defined as the percentage of extracted
EPA with respect to the total amount of EPA contained in the original biomass (Eq. 3).

EPA yield $(w t \%)=\frac{(100 \times \text { EPA recovered in the extract })}{\text { EPA contained in the original biomass }}$

\section{Determination of neutral saponifiable lipids, glycolipids, and phospholipids}

The TLs extracted from the microalgal biomass and some of the hexane and ethanol lipidic extracts were separated into neutral saponifiable lipids (NSLs), glycolipids (GLs), and phospholipids (PLs) following the Kates (1986) procedure. This fractionation was carried out by eluting the microalgal lipids in silica gel cartridges. Samples with around $10 \mathrm{mg}$ of SLs were evaporated under a nitrogen stream and resuspended in $0.5 \mathrm{~mL}$ of chloroform. The samples were loaded into the cartridge and eluted with $30 \mathrm{~mL}$ of chloroform to collect the NSL fraction. Then, $30 \mathrm{~mL}$ of acetone was used along with $20 \mathrm{~mL}$ of chloroform/methanol $(85: 15 v / v)$ to collect the GLs, and finally, $30 \mathrm{~mL}$ of methanol was used to elute the PL fraction. The GC analysis of all fractions gave the percentage of each lipid class with respect to the total SLs and their fatty acid profile (Jiménez Callejón et al. 2014).

\section{Statistical analysis}

All the experiments and analyses were carried out at least twice and the results were expressed as the arithmetic mean \pm the standard deviation. The results were evaluated in terms of ANOVA using Statgraphics 18 Software. $P$ values below 0.05 were considered statistically significant.

\section{Results and discussion}

\section{Lipidic composition of the microalgal biomass}

The Nannochloropsis sp. microalgal biomass used contained $15.0 \pm 0.4 \mathrm{wt} \%$ of SLs and $25.7 \pm 0.7 \mathrm{wt} \%$ of TLs (both with respect to the biomass dry weight). Figure $2 \mathrm{a}$ shows the fatty acid composition of the SLs from the Nannochloropsis sp.: EPA (20:5n3) accounted for $22.1 \pm 0.0 \mathrm{wt} \%$ of the total fatty acids. Polar lipids were much richer in the EPA (49.4 \pm $0.4 \mathrm{wt} \%$ GLs and $18.3 \% \pm 0.2 \mathrm{wt} \%$ PLs of the total fatty acids in each lipid class) than the NSLs $(6.3 \pm 0.3 \mathrm{wt} \%)$ (Fig. 2a). On the other hand, the fractionation of TLs extracted from the biomass resulted in $53.0 \pm 0.9 \mathrm{wt} \%$ of SLs being NSLs, 32.8 $\pm 1.7 \mathrm{wt} \%$ being GLs, and $14.2 \pm 0.7 \mathrm{wt} \%$ being PLs (Fig. 3a, original biomass). This means that $85 \%$ of the total EPA is contained in the polar lipids (73.3\% in GLs and $11.8 \%$ in PLs; Fig. 2b). This is common in photoautotrophic algae because 
the PUFAs in them are mainly accumulated in complex polar lipids constituting the membranes (López et al. 1998; Guihéneuf et al. 2015). This means that the polar lipid concentration or the fractionation of SLs into NSLs and polar lipids occurs alongside a certain EPA concentration in the polar-lipid fraction.

\section{Previous results regarding microalgal lipid extraction}

In our work, the lipid extraction was carried out using lowtoxicity solvents such as hexane and ethanol (96\%), which are allowed in the manufacture of food products. Table 1 shows the results of the SL extraction from $N$. gaditana microalgal biomass carried out in a previous work (Jiménez Callejón et al. 2014). This table shows that, using hexane, SLs were extracted with a yield of $56.7 \%$, a value a little smaller than the percentage of NSLs in the biomass $(65.4 \%)$. The fractionation of extracted SLs showed that $88.2 \%$ of these were NSLs and only $11.8 \%$ were polar lipids (GLs in this case; PLs were not detected in this extract). These results were obtained from a $N$. gaditana batch that contained $24.1 \%$ TLs and $12.0 \%$ SLs (both in biomass dry weight), similar to the contents of the biomass used in this work. Predictably, if hexane (a non-polar solvent, $\log P=4$, Sangster 1989) is used in the first extraction step, it is mainly NSLs that are extracted; thus, we can next extract the polar lipids from the residual biomass using a more polar solvent such as ethanol $(\log P=-0.30)$. In this way, we can separate NSLs and polar lipids. In fact, in recent research work on SL extraction from $N$. gaditana biomass with ethanol (96\%) (Jiménez Callejón et al. 2020), the GL and PL yields obtained were over $99 \%$ when extraction was carried out from lyophilized $N$. gaditana biomass at $20^{\circ} \mathrm{C}$ for $24 \mathrm{~h}$; however, in this case, these polar lipids were extracted together with NSLs.

\section{Simultaneous extraction and fractionation of microalgal lipids from Nannochloropsis sp. lyophilized biomass}

Taking these previous results into account, we planned experiments carrying out a first extraction with hexane and then a second extraction from the residual biomass using ethanol (96\%). In the first hexane extraction step, we primarily expected to extract NSLs with a low EPA content (around 6.3\% of total fatty acids; Fig. 2a) while in the second extraction step
Fig. 2 Lipid composition of Nannochloropsis sp. microalgal biomass: a fatty acid composition (weight percentage of total fatty acids) of total saponifiable lipids (SLs) and of each of the lipidic classes ( NSLs, $\boldsymbol{\square}$ GLs, and $\square$ PLs) obtained by fractionation of TLs; b percentage of EPA in each of the lipidic classes (wt\% with respect to the total EPA in the biomass). Data are shown as mean $\pm \mathrm{SD}, n=3$. When bars do not appear, standard deviations are smaller than the symbols
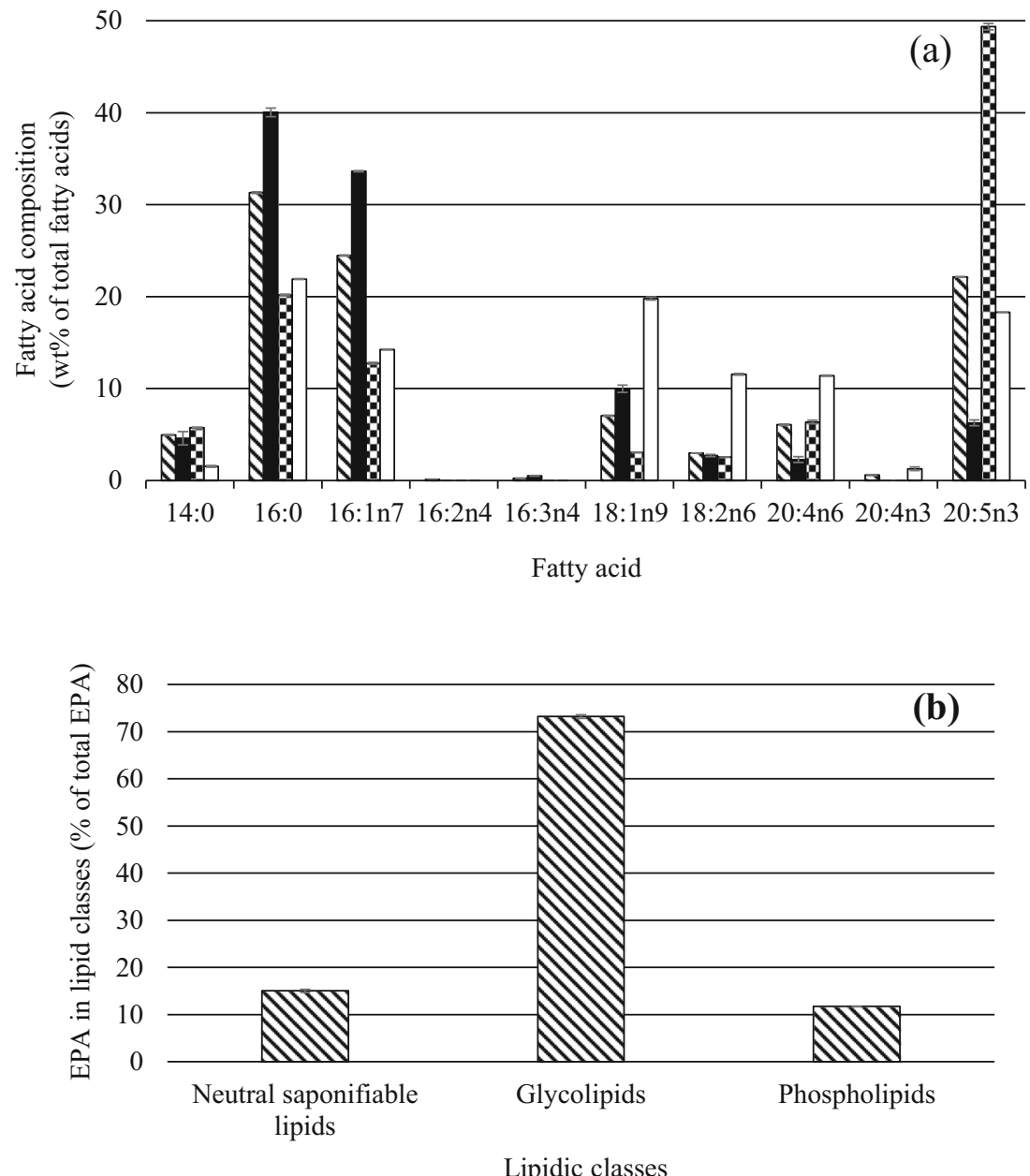
Fig. 3 SL extraction from Nannochloropsis sp. lyophilized biomass using hexane and from residual biomass (previously extracted with hexane) using ethanol. a NSL, $\mathbf{Q}$ GL, and $\square$ PL content (wt\% with respect to total SLs) of original biomass and of the different hexanic and ethanolic extracts obtained under different operational conditions (experiments 2 and 6; Table 3). b - NSL, $\mathbf{G} \mathrm{GL}, \square \mathrm{PL}$, and $\mathbf{\nabla} \mathrm{EPA}$ yield (wt\% with respect to the total contained in the original biomass) in the previously indicated hexanic and ethanolic extracts. Data are shown as mean $\pm \mathrm{SD}, n=2$. When bars do not appear, standard deviations are smaller than the symbols. ${ }^{\text {a, b, c, d }}$ show significant differences in lipidic class content and lipid yield between extracts or experiments with a different letter $(\alpha=0.05)$

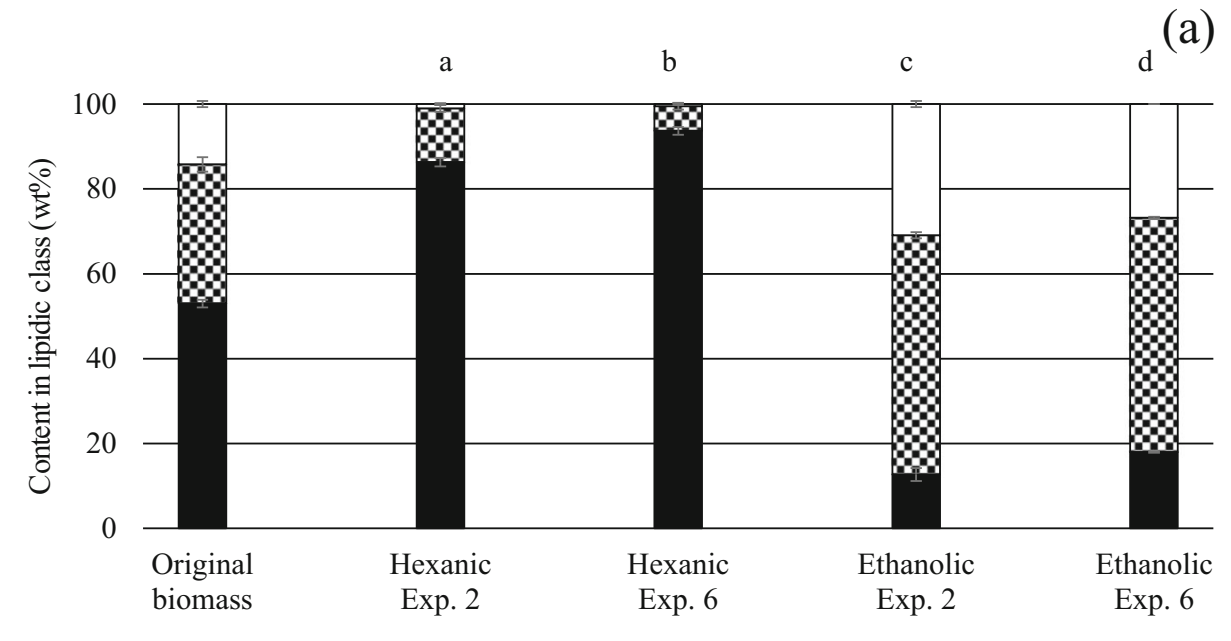

(b)

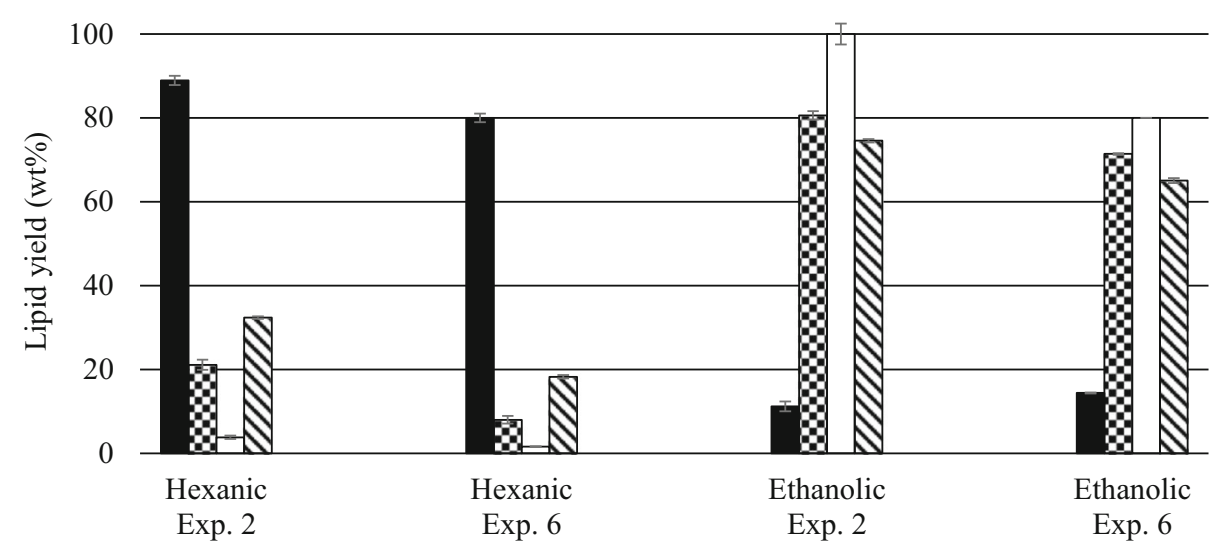

Table 1 Previous results regarding microalgal lipid extraction using hexane: (A) composition in lipidic classes and EPA content of SLs, NSLs, GLs, and PLs of Nannochloropsis gaditana microalgal biomass (Jiménez Callejón et al. 2014). (B) Extraction of SLs: SL yield, composition in lipidic classes and EPA content of the extracted lipidic classes

\begin{tabular}{llllr}
\hline & SLs & NSLs & \multicolumn{1}{l}{ GLs } & \multicolumn{1}{l}{ PLs } \\
\hline (A) & & & & \\
Lipidic species (wt\%) & 100 & $65.4 \pm 1.1$ & $31.2 \pm 1.1$ & $3.4 \pm 0.0$ \\
EPA content (wt\%) & $24.8 \pm 0.3$ & $20.6 \pm 0.0$ & $33.8 \pm 0.1$ & $23.7 \pm 0.0$ \\
(B) & & & & \\
SL yield (wt\%) & $56.7 \pm 0.0$ & & & \\
Lipidic classes (wt\%) & & $88.2 \pm 0.1$ & $11.8 \pm 0.1$ & $0.0 \pm 0.0$ \\
EPA content (wt\%) & $15.8 \pm 0.0$ & $14.8 \pm 0.2$ & $23.7 \pm 0.3$ & \\
\hline
\end{tabular}

Operational conditions: $35.7 \mathrm{~g}$ of wet biomass ( $86 \%$ water; $24.1 \%$ of TLs and $12.0 \%$ of SLs of biomass dry weight) homogenized at 1700 bars, $10 \mathrm{~mL}$ hexane/g dry biomass, $22{ }^{\circ} \mathrm{C}, 20 \mathrm{~h}$

${ }^{\text {a }}$ Of total fatty acid

${ }^{\mathrm{b}}$ Equation (1) with ethanol, we expected to extract mainly EPA-rich polar lipids, thus fractionating the total SLs of the microalgal biomass. In any case, this extraction-fractionation would not be easy because in microalgal cells, the two lipidic species are not completely isolated. Many neutral lipids interact through weak van der Waals forces to form lipid globules in the cytoplasm; these relatively free neutral lipids can be extracted from the cells using non-polar solvents such as hexane, since similar van der Waals forces are formed between the neutral lipids and the non-polar solvent. However, some neutral lipids form complexes with polar lipids, which also form hydrogen bonds with proteins in the cell membrane; non-polar solvents are not capable of disrupting these hydrogen bonds so they cannot extract these complexed neutral lipids and the polar lipids from the cell. In contrast, polar organic solvents can form hydrogen bonds with the lipids from these complexes and hence break the lipid-protein complexes, leading to extraction of the complexed neutral lipids and the polar lipids from the cells (Shahidi and Wanasundara 2002; Halim et al. 2012; Ryckebosch et al. 2014b). 
The two-step extraction was initially applied to lyophilized Nannochloropsis sp. biomass. Table 2 shows the results of the two-step hexane-ethanol (96\%) extraction. Table 2A shows that the SL yield obtained in the first extraction with hexane (49.4\%) was, as expected, quite similar to the NSL content of this biomass $(53.0 \%)$. However, the hexanic fraction contained $12.9 \%$ EPA, a high percentage considering that the NSLs of the biomass contain 6.3\% EPA (Fig. 2a). The fractionation of this hexane extract into NSLs and polar lipids (GLs and PLs) (Table 2B) demonstrated that, as expected, it was very rich in NSLs (73.6\%); however, it also contained an appreciable amount of polar lipids (26.4\%), which explains the high EPA content. The NSLs in this extract contained $6.3 \%$ EPA, exactly the same percentage as that for the NSLs in the biomass. So, by using hexane, not only were the $68.6 \%$ of NSLs contained in the biomass recovered but also the $27.7 \%$ of polar lipids (Table 2B), an excessive amount when considering the objective of this work. Similar results were obtained by Ryckebosch et al. (2014a) from different microalgal species (Isochrysis galbana, Nannochloropsis gaditana, Nannochloropsis sp., and Phaedactylum tricornutum) testing several extraction solvent systems. For all the microalgae tested, the neutral lipid (NL) content in the hexane extract was higher than the content in the original biomass; for example, the hexane extract from Nannochloropsis sp. biomass contained around $80 \%$ of NLs, higher than the NL content of the biomass (46.5\%). In this case, only $35 \%$ of the NLs contained in the biomass were recovered in the hexane extract. Also, similar to our results, polar lipids (GLs and PLs) were found in this hexane extract (19.8\% of polar lipids in the biomass).

In the second extraction with ethanol, the SL yield (37.3\%; Table 2A) was small considering that the biomass contained $47.0 \%$ polar lipids; this result agrees with the relatively high percentage of polar lipids extracted with hexane (27.7\%) and the $13.3 \%$ of SLs still contained in the residual biomass after this second extraction step (Table 2A; Fig. 1). Consequently, new conditions should be tested to increase this last SL yield. The ethanolic extract contained 31.3\% EPA (Table 2A), which is lower than the average EPA content in the polar lipids (40.0\%; calculated from the EPA content of GLs, $49.4 \%$, and PLs, $18.3 \%$, Fig. 2a). This ethanolic extract contained $72.5 \%$ polar lipids and $27.4 \%$ NSLs (Table 2B), which means that $57.6 \%$ of the total polar lipids were recovered in this extract. It is difficult to compare these results with the ones obtained by other authors because few works were found that carried out a sequential lipid extraction from the microalgal biomass with the goal of clearly separating NLs and polar lipids. Castejón and Señoráns (2019) carried out a three-step consecutive extraction on $N$. gaditana biomass using pressurized solvents with the aim of obtaining fractions of decreasing polarity: a first extraction with water at $60{ }^{\circ} \mathrm{C}$ to eliminate polar compounds, such as carbohydrates or peptides, a second extraction with ethanol at $90{ }^{\circ} \mathrm{C}$ to extract polar lipids, and a third with hexane at $120{ }^{\circ} \mathrm{C}$ to extract the non-polar lipids. However, after the ethanol extraction (step 2), the biomass was exhausted (a $12.6 \%$ extraction yield of biomass dry weight), and in the following hexane extraction step, a low lipid yield was obtained (1.3\%). This result is consistent with data from the literature since ethanol can extract both NLs and polar lipids from $N$. gaditana biomass at high yields of up to 99\% (Jiménez Callejón et al. 2020).

Using this procedure, we obtained an hexanic extract appreciably richer in NSLs (73.6\%) than SLs from the biomass (53.0\%) and an ethanolic extract with $72.5 \%$ polar lipids (appreciably higher than the biomass polar lipid content, $47.0 \%$ ); furthermore, this ethanolic extract contained $31.3 \% \mathrm{EPA}$ (appreciably higher than the $22.1 \%$ of EPA in the biomass). The polar lipids and EPA recovery yields in the ethanolic extract were, respectively, $57.6 \%$ (of the polar lipids contained in the biomass) and $52.8 \%$ (of the EPA contained in the biomass; or $62.1 \%$ of the EPA contained in the biomass polar lipids). These results support the objective of this work because we were able to obtain a polar lipid and EPA-enriched ethanolic extract.

\section{Optimization of the hexane-ethanol extraction steps from the lyophilized biomass}

To improve the previous results, a study on the extraction conditions for both steps was carried out. Table 3 and Fig. 3 show the results of the experiments to optimize both the hexane and ethanol extraction steps, with the aim of finding more appropriate values for the temperature, time, and solvent/ biomass ratio, required for attaining high NSL and polar lipid yields when extracting with hexane and ethanol, respectively.

Table 3A shows that, in the SL extraction with hexane, increasing the extraction temperature from 20 to 40 and $60{ }^{\circ} \mathrm{C}$ (experiments 1 to 3 ) increased the SL yield to a maximum value of $54.6 \%$ at $40{ }^{\circ} \mathrm{C}$ (for $20 \mathrm{~h}$ and $30 \mathrm{~mL}$ hexane $\mathrm{g}^{-1}$ biomass). Hence, this temperature was chosen to study the influence of the hexane/biomass ratio. Experiment 2 and experiments 4 to 6 show that a SL yield of $54.0 \%$ was achieved using only $10 \mathrm{~mL}$ hexane $\mathrm{g}^{-1}$ biomass (no significant differences were obtained between the SL yields achieved with 10,20 , and $30 \mathrm{~mL} \mathrm{~g}^{-1}$ ). When this ratio was reduced to $5 \mathrm{~mL} \mathrm{~g}^{-1}$ biomass, the SL yield decreased to $45.3 \%$. In an attempt to reduce the extraction time as well, extraction was carried out at $40^{\circ} \mathrm{C}, 10 \mathrm{~mL} \mathrm{~g}^{-1}$ for $8 \mathrm{~h}$ (experiment 7); however, under these conditions, the SL yield likewise decreased to $44.0 \%$. Then, to carry out extractions using short reaction times, three experiments were carried out at $60{ }^{\circ} \mathrm{C}$, $10 \mathrm{~mL} \mathrm{~g}^{-1}$ for times of 1,4 , and $8 \mathrm{~h}$ (experiments 8 to 10 ). These experiments show that at $60^{\circ} \mathrm{C}, 8 \mathrm{~h}$, and $10 \mathrm{~mL} \mathrm{~g}^{-1}$, an SL yield of $55.6 \%$ was obtained, similar to that achieved at $40{ }^{\circ} \mathrm{C}, 20 \mathrm{~h}$, and $10 \mathrm{~mL} \mathrm{~g}^{-1}$ (54.0\%). Therefore, similar SL yields can be achieved under different condition combinations. It seems 
Table 2 Simultaneous extraction and fractionation of microalgal lipids from Nannochloropsis sp. lyophilized biomass by sequential extraction hexane-ethanol $(96 \%$ $v / v)$ : (A) SL yields and EPA content in the hexanic and ethanolic extracts and in the residual biomass II (not extracted lipids). (B) Composition in lipidic classes, recovery of NSLs and polar lipids and EPA content of each lipidic class of both extracts

\begin{tabular}{lccc}
\hline & Hexanic extract & Ethanolic extract & Residual biomass II \\
\hline (A) & & & \\
SL yield (wt\%) & $49.4 \pm 0.2$ & $37.3 \pm 1.2$ & $33.3 \pm 0.1$ \\
EPA content (wt\%) $^{\mathrm{b}}$ & $12.9 \pm 0.0$ & $31.3 \pm 0.7$ & \\
(B) & & & \\
Composition in lipidic classes (wt\%) & & & \\
NSLs & $73.6 \pm 0.3$ & $27.4 \pm 1.1$ & \\
GLs & $12.7 \pm 0.7$ & $41.8 \pm 1.5$ & \\
PLs & $13.7 \pm 0.3$ & $30.7 \pm 0.4$ & \\
Lipid yield (wt\%) & & & \\
NSLs & $68.6 \pm 0.3$ & $19.3 \pm 0.8$ & \\
Polar lipids & $27.7 \pm 0.3$ & $57.6 \pm 0.9$ & \\
EPA content $(w t \%)^{d}$ & & $9.4 \pm 3.1$ & \\
NSLs & $6.3 \pm 0.1$ & $48.7 \pm 0.3$ & \\
GLs & $46.7 \pm 2.4$ & $16.9 \pm 0.0$ & \\
PLs & $12.9 \pm 0.6$ & & \\
\hline
\end{tabular}

Operational conditions: $2.5 \mathrm{~g}$ of lyophilized biomass ( $15.0 \pm 0.4 \mathrm{w} \%$ of SLs, $22.1 \pm 0.0 \mathrm{wt} \%$ of the EPA in the total fatty acids, section "Lipidic composition of the microalgal biomass"). Hexane extraction: $75 \mathrm{~mL}$ hexane, $20 \mathrm{~h}, 20^{\circ} \mathrm{C}, 300 \mathrm{rpm}$. Ethanol extraction: $75 \mathrm{~mL}$ ethanol $(96 \%), 20 \mathrm{~h}, 20^{\circ} \mathrm{C}, 300 \mathrm{rpm}$

${ }^{\mathrm{a}}$ Equation (1)

${ }^{\mathrm{b}}$ Of total fatty acid

${ }^{\mathrm{c}}$ Equation (2) clear that the optimal conditions, producing similarly high SL yields (around 54.0-55.6\%), will be obtained from economically balancing the considerations of energy consumption (related to temperature and time) and solvent consumption.

An extraction experiment using $40{ }^{\circ} \mathrm{C}, 20 \mathrm{~h}$, and $10 \mathrm{~mL} \mathrm{~g}^{-1}$ (experiment 11) was performed using $50 \mathrm{~g}$ of lyophilized biomass instead of the $2.5 \mathrm{~g}$ used in all previous experiments (a scaling-up factor of 20). Similar SL yields were obtained under the same conditions for both scales $(54.0 \%$, Exp. 5 and $52.9 \%$, Exp. 11). These maximum SL yields were similar to the NSL content of the biomass $(53.0 \%)$ and close to the SL yield achieved by Soxhlet extraction (57.9\%, experiment 12; Table 3), which would indicate that good extraction of this lipid type could have been achieved using hexane. However, these extracts contained 9.1-14.9\% EPA, duplicating the EPA content of the NSLs (6.3\%; Fig. 2a).

To gain insight into the lipid class composition of the extracted fractions, two of these extracts were fractionated into NSLs, GLs, and PLs (Fig. 3). The hexanic extract obtained at $40{ }^{\circ} \mathrm{C}$, $20 \mathrm{~h}$, and $30 \mathrm{~mL} \mathrm{~g}^{-1}$ (Exp. 2, 54.6\% SL yield) contained $86.3 \%$ NSLs and only $13.7 \%$ polar lipids (Fig. 3a); $88.9 \%$ of the NSLs contained in the original biomass were extracted (Fig. 3b) and these NSLs contained 6.3\% EPA (the same value as the NSLs in the original biomass); however, $21.1 \%$ of the GLs and $3.8 \%$ of the PLs contained in the biomass were also extracted (Fig. 3b), which means that $32.4 \%$ of the biomass EPA was extracted (Fig. $3 \mathrm{~b}$; EPA content of this extract was $13.1 \%$; Table $3 \mathrm{~A})$. In addition, we fractionated the hexane extract from the extraction carried out at $40{ }^{\circ} \mathrm{C}, 20 \mathrm{~h}$ and only $5 \mathrm{~mL} \mathrm{~g}^{-1}$, which resulted in a lower SL yield of $45.3 \%$ (Exp. 6). In this case, the hexanic extract contained $93.7 \%$ NSLs (Fig. 3a), although a lower percentage of the NSLs contained in the biomass were extracted (80.0\%; Fig. 3b). Comparing the results of experiments 6 and 2 indicates that the higher the SL extraction yield (45.3 and 54.6, respectively; Table $3 \mathrm{~A}$ ), the higher the NSL yield (80.0 and $88.9 \%$, respectively; Fig. 3 b) but also the more polar lipids were extracted (especially GLs, with polar lipid yields of $24.9 \%$ and $9.6 \%$ in experiments 6 and 2, respectively; Fig. 3b), which decreased the NSL percentage in the hexanic extract $(93.7 \%$ and $86.3 \%$, respectively). Therefore, if high NSL yields are preferred, we should choose conditions under which the SL extraction yield is high (experiment 2, with a high hexane/biomass ratio). Conversely, if we prefer to obtain an extract rich in NSLs (Fig. 2a), we should choose conditions under which the SL extraction yields are moderate (experiment 6 , with a lower hexane/biomass ratio). In any case, under the conditions specified, very rich NSL hexanic extracts were obtained (86.3-93.7\% NSLs) with high recoveries of these lipids (above $80 \%$ ).

Subsequently, five of the residual biomasses from the hexanic extractions (experiments 2, 3, 5, 6, and 11; Table 3A) were subjected to a second extraction step with ethanol (96\%) (Table 3B). Each of these five ethanol extractions was performed under the same conditions of temperature, time, and solvent/dry biomass ratio as the first hexane extraction step (Table 3A). Table 3B shows that, for experiments 2 and 3 (carried out by modifying the temperature), similar SL yields were achieved; so, under these 
Table 3 SL extraction from (A) lyophilized Nannochloropsis sp. biomass using hexane and (B) residual biomass of

Nannochloropsis sp. previously extracted with hexane, using ethanol, under different conditions: the influence of temperature, time, and solvent/biomass ratio on the SL yield and EPA content

\begin{tabular}{|c|c|c|c|c|c|}
\hline (A) Exp. & $\mathrm{T}\left({ }^{\circ} \mathrm{C}\right)$ & $\mathbf{T}$ (h) & Hexane/biomass ratio $\left(\mathrm{mL} \mathrm{g}^{-1}\right)$ & SL yield $(w t \%)^{1}$ & $\begin{array}{l}\text { EPA content } \\
(w t \%)^{2}\end{array}$ \\
\hline 1 & 20 & 20 & 30 & $49.4 \pm 0.2^{\mathrm{a}}$ & $12.9 \pm 0.0$ \\
\hline 2 & 40 & 20 & 30 & $54.6 \pm 2.2^{\mathrm{b}, \mathrm{c}}$ & $13.1 \pm 2.1$ \\
\hline 3 & 60 & 20 & 30 & $54.3 \pm 0.5^{\mathrm{b}, \mathrm{c}}$ & $13.1 \pm 0.2$ \\
\hline 4 & 40 & 20 & 20 & $53.9 \pm 0.4^{\mathrm{b}, \mathrm{c}}$ & $13.8 \pm 0.2$ \\
\hline 5 & 40 & 20 & 10 & $54.0 \pm 0.4^{\mathrm{b}, \mathrm{c}}$ & $13.6 \pm 0.1$ \\
\hline 6 & 40 & 20 & 5 & $45.3 \pm 0.9^{\mathrm{d}}$ & $8.9 \pm 0.2$ \\
\hline 7 & 40 & 8 & 10 & $44.0 \pm 1.4^{\mathrm{d}}$ & $8.8 \pm 0.1$ \\
\hline 8 & 60 & 8 & 10 & $55.6 \pm 1.0^{\mathrm{c}}$ & $14.9 \pm 0.1$ \\
\hline 9 & 60 & 4 & 10 & $49.1 \pm 0.7^{\mathrm{a}}$ & $11.9 \pm 0.3$ \\
\hline 10 & 60 & 1 & 10 & $44.5 \pm 0.1^{\mathrm{d}}$ & $9.1 \pm 0.2$ \\
\hline $11 *$ & 40 & 20 & 10 & $52.9 \pm 0.5^{b}$ & $13.5 \pm 0.1$ \\
\hline 12 & Soxhlet & 8 & Soxhlet & $57.9 \pm 3.9^{\mathrm{e}}$ & $17.5 \pm 0.3$ \\
\hline (B) Exp. & $\mathrm{T}\left({ }^{\circ} \mathrm{C}\right)$ & $\mathbf{T}$ (h) & $\begin{array}{l}\text { Ethanol/biomass ratio } \\
\qquad\left(\mathrm{mL} \mathrm{g}^{-1}\right)\end{array}$ & SL yield $(\%)^{1}$ & $\begin{array}{l}\text { EPA content } \\
(w t \%)^{2}\end{array}$ \\
\hline 2 & 40 & 20 & 30 & $46.8 \pm 0.1^{\mathrm{a}^{\prime}}$ & $35.2 \pm 0.3$ \\
\hline 3 & 60 & 20 & 30 & $46.1 \pm 0.8^{a^{\prime}}$ & $33.4 \pm 0.6$ \\
\hline 5 & 40 & 20 & 10 & $43.3 \pm 0.3^{b^{\prime}}$ & $35.0 \pm 0.2$ \\
\hline 6 & 40 & 20 & 5 & $42.4 \pm 1.1^{\mathrm{b}^{\prime}}$ & $33.9 \pm 0.1$ \\
\hline 11 & 40 & 20 & 10 & $42.9 \pm 0.1^{\mathrm{b}^{\prime}}$ & $35.2 \pm 0.1$ \\
\hline
\end{tabular}

Operational conditions: (A) 2.5 g of lyophilized biomass (section "Lipidic composition of the microalgal biomass"), $300 \mathrm{rpm}$. *50 g of biomass. (B) Residual biomass from the hexanic extractions, $300 \mathrm{rpm}$

${ }^{1}$ Equation (1)

${ }^{2}$ Of total fatty acid

a, b, c, d, e No significant differences in SL yield between the hexanic extracts with the same letter $(\alpha=0.05)$

${ }^{\prime}, b^{\prime}$ No significant differences in SL yield between the ethanolic extracts with the same letter $(\alpha=0.05)$. Data are shown as mean $\pm \mathrm{SD}, n=2$ conditions $\left(20 \mathrm{~h}\right.$ and $\left.30 \mathrm{~mL} \mathrm{~g}^{-1}\right)$, the lower $40{ }^{\circ} \mathrm{C}$ temperature was preferable (experiment 2). Experiments 2, 5, and 6 (carried out by modifying only the ethanol/biomass ratio) show that small decreases in the SL yields were observed when reducing the ethanol $(96 \%) /$ biomass residue ratio from 30 to 10 and $5 \mathrm{~mL} \mathrm{~g}^{-1}$. Hence, the middle ethanol $(96 \%) /$ biomass ratio of $10 \mathrm{~mL} \mathrm{~g}^{-1}$ was chosen for scaling up. In experiment 11 , the residual biomass from extracting $50 \mathrm{~g}$ of biomass with hexane (a scaling-up factor of 20) was extracted under the same conditions as in experiment $5\left(40^{\circ} \mathrm{C}, 20 \mathrm{~h}\right.$, and $\left.10 \mathrm{~mL} \mathrm{~g}^{-1}\right)$, obtaining a SL yield of $42.9 \%$ (similar to that obtained at the small scale, 43.3\%). Thus, in this larger-scale experiment, a total SL yield of 95.8\% was achieved $(52.9 \%$ with hexane, Table $3 \mathrm{~A}$, and $42.9 \%$ with ethanol, Table 3B). The SL yields shown in Table 3B are similar to, or a little lower than, the polar lipid content of the biomass (32.8\% of GLs and $14.2 \%$ of PLs; Fig. 3a), which would indicate that the ethanol mainly extracted the polar lipids, as previously the hexane had mainly extracted NSLs. The EPA content of these SLs (33.4-35.2\%; Table 3B) was a little lower than the EPA content of the polar lipids (40\%; Fig. 2a).

Three of these ethanolic extracts were fractionated into NSLs, GLs, and PLs (Figs. 3 and 4). The extract obtained in experiment 2 (an SL yield of $46.8 \%$; Table 3B) contained only $12.7 \%$ NSLs and $87.3 \%$ polar lipids (56.4\% of which were GLs and $30.9 \%$ PLs; Fig. 3a) with nearly $81 \%$ of the GLs and the totality of PLs contained in the biomass being extracted (Fig. 3b), and these GLs and PLs contained $42.7 \%$ and $20.0 \%$ EPA, respectively (contents that were very close to the GLs and PLs in the original biomass at 49.4 and $18.3 \%$, respectively; Fig. 2a). We also fractionated the ethanolic extract from the extraction carried out at $40{ }^{\circ} \mathrm{C}, 20 \mathrm{~h}$, and only $5 \mathrm{~mL} \mathrm{~g}^{-1}$ (experiment 6 ; Table $3 \mathrm{~B}$ ), which produced a slightly lower SL yield (42.4\%; Table 3B). In this case, the extract contained $82 \%$ polar lipids (55.2\% GLs and $26.8 \%$ PLs; Fig. 3a); $71 \%$ of the GLs and $80 \%$ of the PLs present in the biomass being extracted (Fig. 3b) - these lower polar lipid yields were possibly due to the lower ethanol/biomass ratio used. Comparing the results of experiments 2 and 6 , we see that, to obtain an ethanolic extract with the highest polar lipid content (87.3\%, experiment 2; Fig. 3a), the NSLs should be extracted with a high yield in the first hexane extraction step, even if this involves a loss in terms of polar lipids. The ethanolic extract from experiment 6 contains less polar lipids ( $82 \%$; Fig. 3a); this is also probably due to the higher NSL content of the biomass residue from which the extraction was performed, since the SL yield (and therefore the NSL yield) in the hexane extraction was lower than in experiment 2. 
Additionally, we fractionated the hexanic and ethanolic extracts from experiment 11 (Table 3A and B). The ethanolic extract was obtained from the biomass residue following the hexane extraction carried out on $50 \mathrm{~g}$ of biomass (experiment 11; Table 3A). The NSL, GL, and PL composition of this ethanolic SL extract is shown in Fig. 4a, the composition of which was similar to that in experiment 2 (the differences between the NSL, GL, and PL compositions of both ethanolic extracts not being significant; Figs. $3 a$ and $4 a$ ); nonetheless, lower polar lipid recoveries were obtained (76.5\% GLs and $88.2 \%$ PLs; Fig. $4 \mathrm{~b}$ ), which was due to the lower ethanol/biomass ratio used in this case $(10 \mathrm{~mL}$ ethanol/g and $30 \mathrm{~mL} / \mathrm{g}$ used in experiment 2 ). In this scaled-up experiment, the SL fraction contained $87.7 \%$ polar lipids (Fig. 4a) and $35.2 \%$ EPA (Table 3B) while $80 \%$ of the polar lipids contained in the biomass were recovered (Fig. $4 \mathrm{~b}$ ).

Figures 3 and 4 therefore show how effectively we obtained hexanic extracts using this procedure, with an NSL content up to
$86.3-93.7 \%$ and where $88.9-80.0 \%$ of the NSLs contained in the biomass were recovered; these NSL contents are considerably higher than the NSL content of the biomass (53.0\%) and much higher than that achieved in the first fractionation experiment (73.6\% NSLs; Table 2). These figures also show that an ethanolic fraction with up to $87.3-87.7 \%$ polar lipids (56.4\% GLs, 30.9\% PLs) and around 35.2\% EPA (Table 3B) was obtained, considerably higher than the polar lipid and EPA content of the biomass (47 and $22.1 \%$, respectively) and that achieved in the first fractionation experiment $(72.5 \%$ and $31.3 \%$, respectively; Table 2$)$. In terms of EPA, $65.0-74.7 \%$ of that contained in the biomass was recovered in the ethanolic fractions. Thus, the proposed methodology (summarized in Fig. 1) allows us to obtain EPArich polar lipid concentrates from the simultaneous extraction and fractionation of the SLs present in the Nannochloropsis sp. microalga using an extraction solvent which is permitted in the food industry. For this, it is essential to achieve SL yields close to the NSL content of the original biomass in the first hexane
Fig. 4 Comparison between the simultaneous extraction and fractionation of microalgal lipids from Nannochloropsis sp. lyophilized and wet biomass in two steps using hexane and ethanol. a $\square \mathrm{NSL}, \boldsymbol{G L}$, and $\square$ PL content (wt $\%$ with respect to the total SLs) of the original biomass and the hexanic and ethanolic extracts obtained from lyophilized biomass (experiment 11 ; Table 3) and from wet biomass ( $86 \mathrm{wt} \%$ water) obtained under the same operational conditions $\left(40^{\circ} \mathrm{C}, 20 \mathrm{~h}\right.$, and using $10 \mathrm{~mL}$ of solvent/g equivalent dry biomass). b a NSL, $\mathbf{\square G L}, \square \mathrm{PL}$, and $\mathbf{E P A}$ yield (wt\% with respect to the total contained in the original biomass) in previously indicated hexanic and ethanolic extracts. Data are shown as mean $\pm \mathrm{SD}, n=2$. When bars do not appear, standard deviations are smaller than the symbols. ${ }^{\mathrm{a}, \mathrm{b}}$,

$\mathrm{c}, \mathrm{d}$ show significant differences in lipidic class content and lipid yield between extracts or experiments with a different letter $(\alpha=0.05)$

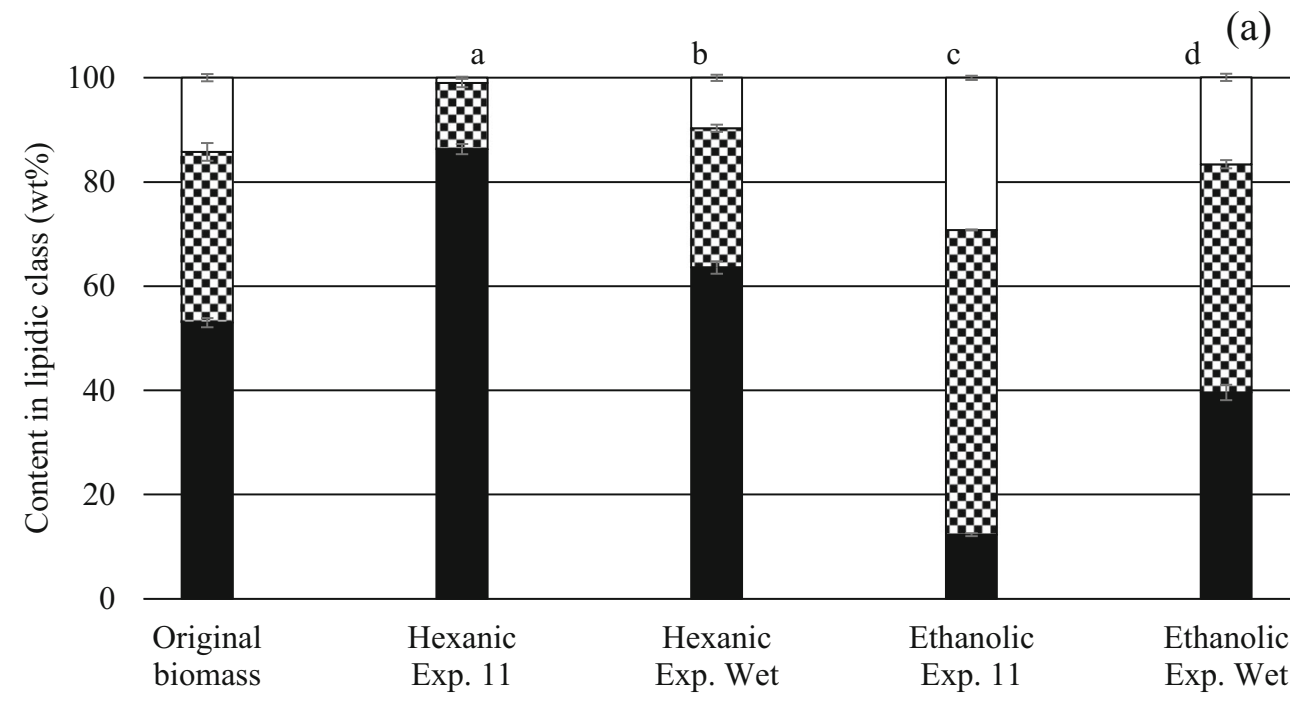

(b)

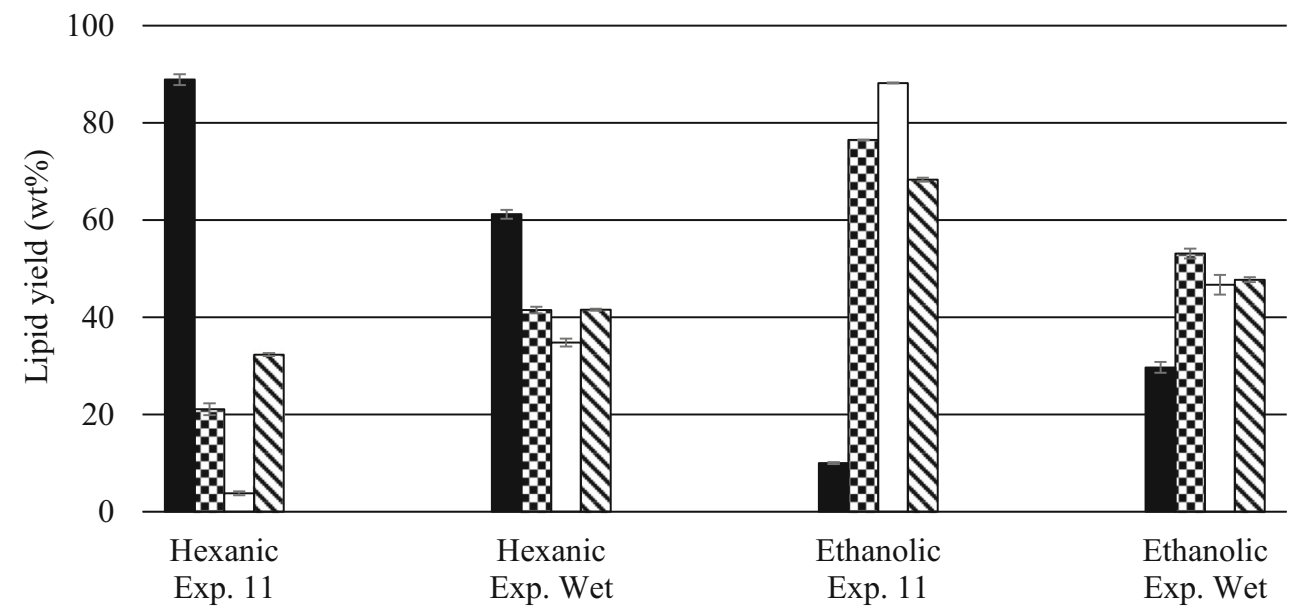


extraction step so that the biomass is practically exhausted of NSLs. The subsequent extraction with ethanol from the residual biomass ensures an extract which not only contains high polar lipid yields from the biomass, but also an EPA-enriched extract (since this fatty acid is mainly located in the polar lipids).

\section{Extraction-fractionation of SLs from wet Nannochloropsis sp. biomass}

Generally, microalgal biomass lyophilization is considered to be an expensive operation because it requires costly equipment and consumes an appreciable amount of energy. From wet biomass, higher solvent/biomass ratios are usually required to achieve similar SL yields. In this respect, Malekzadeh et al. (2016) demonstrated that the SL extraction yield from Chlorella vulgaris using different hexane-methanol mixtures (from 1:0 to 0:1 v/v) was lower, the higher the biomass water content (these authors tested lyophilized and wet biomasses with $70 \%$ and $80 \%$ water contents); the reduction in yield being more intense when hexane was the dominant portion of the solvent mixture. Moreover, the ethanol recovery costs were greater using wet biomass since the ethanol have to be separated from a great amount of water (Jiménez Callejón et al. 2020).

In any case, to compare the previous results obtained using lyophilized biomass, the two-step hexane-ethanol (96\%) extraction procedure was applied to wet biomass with a water content of $86 \mathrm{wt} \%$, which is a typical water content after the biomass harvested from the photobioreactor is centrifuged. The two extraction steps were carried out at $40{ }^{\circ} \mathrm{C}$ for $20 \mathrm{~h}$ using $10 \mathrm{~mL}$ of solvent/g of equivalent dry biomass (the same conditions as in experiments 5 and 11; Table 3 ). In this experiment, the hexane and ethanol SL extraction yields were 51.0 and $39.8 \%$, respectively; a little lower than the yields obtained from dry biomass under the same conditions (54.0 and 43.3\%, respectively; Table 3), which is logical given the presence of water. The EPA content of the hexane and ethanolic extracts were 18.0 and $26.5 \%$ higher and lower, respectively, than the EPA contents of the extracts obtained from lyophilized biomass (13.5 and 35.2\%, respectively; Table 3). Figure 4 compares the results of this extraction-fractionation experiment (Hexanic Exp. Wet, Ethanolic Exp. Wet) with that previously obtained from the lyophilized biomass (Hexanic Exp. 11, Ethanolic Exp. 11). This figure shows that the separation of both lipidic species was worse than when using lyophilized biomass even though the NSLs and polar lipids were mostly extracted in the hexane and ethanol extract, respectively. In this case, the SL extracted with hexane contained $63.6 \%$ NSL (Fig. 4a), and only $61.2 \%$ of the NSLs contained in the biomass were extracted (Fig. 4b). The ethanol fraction contained $60.5 \%$ polar lipids (Fig. 4a; Ethanolic Exp. Wet), and only $53.1 \%$ of the GLs and $47.7 \%$ of the PLs contained in the biomass were extracted with ethanol; both percentages being considerably lower than the 76.5 and $88.2 \%$ achieved, respectively, from the lyophilized biomass (Ethanolic exp. 11; Fig. 4b). Perhaps the presence of water decreased the selectivity of hexane and ethanol towards neutral and polar lipids, respectively. On the other hand, other reasons might influence this poorer separation of both lipid species. Firstly, the SL extraction yields were lower than those achieved from lyophilized biomass due to the presence of water. In this regard, with the wet biomass, we used the extraction conditions optimized for lyophilized biomass whereas the wet biomass might require different extraction conditions; for example, higher solvent/biomass ratios. Consequently, further experiments need to be carried out with wet biomass, similar to those shown in Table 3, if we wish to improve the separation of NSLs and polar lipids.

\section{Conclusions}

A procedure was developed to extract SL fractions rich in NSLs and EPA-enriched polar lipids (GLs and PLs) from Nannochloropsis sp. lyophilized biomass. Under the optimal conditions in a first hexane extraction step, an SL extract with 86.3-93.7\% NSLs was obtained; this extract contained 88.9 $80.0 \%$ of the NSLs present in the biomass. Subsequently, in a second extraction step with ethanol (96\%), an SL extract was obtained with $82.0-87.7 \%$ polar lipids and up to $35.2 \%$ EPA. This SL extract contained up to $87.1 \%$ of the polar lipids and $74.7 \%$ of the EPA present in the Nannochloropsis sp. biomass.

Funding information This research was supported by grants from the Ministerio de Economía, Industria y Competitividad (Spain), Project CTQ2017-85613-R which, in turn, was co-funded by FEDER (The European Regional Development Fund).

Open Access This article is licensed under a Creative Commons Attribution 4.0 International License, which permits use, sharing, adaptation, distribution and reproduction in any medium or format, as long as you give appropriate credit to the original author(s) and the source, provide a link to the Creative Commons licence, and indicate if changes were made. The images or other third party material in this article are included in the article's Creative Commons licence, unless indicated otherwise in a credit line to the material. If material is not included in the article's Creative Commons licence and your intended use is not permitted by statutory regulation or exceeds the permitted use, you will need to obtain permission directly from the copyright holder. To view a copy of this licence, visit http://creativecommons.org/licenses/by/4.0/.

\section{References}

Adarme-Vega TC, Thomas-Hall SR, Schenk PM (2014) Towards sustainable sources for omega-3 fatty acids production. Curr Opin Biotechnol 26:14-18

Antonopoulos E, Freisleben H-J, Krisnamurti DGB, Estuningtyas A, Mulyanto C, Ridwan R, Freisleben SKU (2013) Fractionation and purification of membrane lipids from the archaeon Thermoplasma acidophilum DSM 1728/10217. Sep Purif Technol 110:119-126 
Burri L, Johnsen L (2015) Krill products: an overview of animal studies. Nutrients 7:3300-3321

Burri L, Hoem N, Banni S, Berge K (2012) Marine omega-3 phospholipids : metabolism and biological activities. Int J Mol Sci 13: 15401-15419

Calder PC (2012) The role of marine omega-3 (n-3) fatty acids in inflammatory processes, atherosclerosis and plaque stability. Mol Nutr Food Res 56:1073-10180

Castejón N, Señoráns FJ (2019) Simultaneous extraction and fractionation of omega-3 acylglycerols and glycolipids from wet microalgal biomass of Nannochloropsis gaditana using pressurized liquids. Algal Res 37:74-82

Chisti Y (2007) Biodiesel from microalgae. Biotechnol Adv 25:294-306

Christie WW (2003) Lipid analysis - isolation, separation, identification and structural analysis of lipids, 3rd edn. The Oily Press, Bridgwater, UK

Chua E, Schenk P (2017) A biorefinery for Nannochloropsis: induction, harvesting, and extraction of EPA-rich oil and high-value protein. Bioresour Technol 244:1416-1424

Da Costa E, Silva J, Mendonca SH, Abreu MH, Domingues MR (2016) Lipidomic approaches towards deciphering glycolipids from microalgae as a reservoir of bioactive lipids. Mar Drugs 14:101

Devos M, Poisson L, Ergan F, Pencreac'h G (2006) Enzymatic hydrolysis of phospholipids from Isochrysis galbana for docosahexaenoic acid enrichment. Enz Microb Technol 39:548-554

Finco AMDO, Mamani LDG, Carvalho JCD, de Melo Pereira GV, Thomaz-Soccol V, Soccol CR (2017) Technological trends and market perspectives for production of microbial oils rich in omega-3. Crit Rev Biotechnol 37:656-671

Ghasemifard S, Turchini GM, Sinclair AJ (2014) Omega-3 long chain fatty acids "bioavailability": a review of evidence and methodological considerations. Prog Lipid Res 56:92-108

Guihéneuf F, Schmid M, Stengel DB (2015) Lipids and fatty acids in algae: extraction, fractionation into lipid classes, and analysis by gas chromatography coupled with flame ionization detector (GC-FID). In: Dagmar B, Stengel DB, Connan S (eds) Natural products from marine algae: methods and protocols. Springer, New York, pp 173-190

Halim R, Danquah MK, Webley PA (2012) Extraction of oil from microalgae for biodiesel production: a review. Biotechnol Adv 30: 709-732

Jiménez Callejón MJ, Robles Medina A, Macías Sánchez MD, Hita Peña E, Esteban Cerdán L, González Moreno PA, Molina Grima E (2014) Extraction of saponifiable lipids from wet microalgal biomass for biodiesel production. Bioresour Technol 169:198-205

Jiménez Callejón MJ, Robles Medina A, Macías Sánchez MD, Esteban Cerdán L, González Moreno PA, Navarro López E, Hita Peña E, Molina Grima E (2020) Obtaining highly pure EPA-rich lipids from dry and wet Nannochloropsis gaditana microalgal biomass using ethanol, hexane and acetone. Algal Res 45:101729

Kagan ML, West AL, Zante C, Calder PC (2013) Acute appearance of fatty acids in human plasma - A comparative study between polarlipid rich oil from the microalgae Nannochloropsis oculata and krill oil in healthy young males. Lipids Health Dis 12:102-112

Kagan ML, Levy A, Leikin-Frenkel A (2015) Comparative study of tissue deposition of omega-3 fatty acids from polar-lipid rich oil of the microalgae Nannochloropsis oculata with krill oil in rats. Food Funct 6:186-192

Kates M (1986) Techniques of lipidology isolation, analysis, and identification of lipids. Elsevier, Amsterdam, p 190

Kochet G (1978) Quantitation of the macromolecular components of microalgae. In: Hellebust J, Cragie S (eds) Handbook of Phycological Methods. Physiological and Biochemical Methods. Cambridge University Press, Cambridge pp 189-195

Lee JH, O'Keefe JH, Lavie CJ, Harris WS (2009) Omega-3 fatty acids: cardiovascular benefits, sources and sustainability. Nat Rev Cardiol 6:753-758
López D, Belarbi EH, Rodríguez J, Segura CI, Giménez A (1998) Acyl lipids of three microalgae. Phytochemistry 47:1473-1481

Malekzadeh M, Abedini Najafabadi H, Hakim M, Feilizadeh M, Vossoughi M, Rashtchian D (2016) Experimental study and thermodynamic modelling for determining the effect of non-polar solvent (hexane)/polar solvent (methanol) ratio and moisture content on the lipid extraction efficiency from Chlorella vulgaris. Bioresour Technol 201:304-311

Molina E, García F, Acién FG (1999) Production of EPA from Phaeodactylum tricornutum. In: Cohen $\mathrm{Z}$ (ed) Chemicals from microalgae. Taylor \& Francis, London, pp 57-92

Mun S, Decker EA, McClements DJ (2007) Influence of emulsifier type on in vitro digestibility of lipids droplets by pancreatic lipase. Food Res Int 40:770-781

Pottel L, Lycke M, Boterberg T, Foubert I, Pottel H, Duprez F, Goethals L, Debruyne PR (2014) Omega-3 fatty acids: Physiology, biological sources and potential applications in supportive cancer care. Phytochem Rev 13:223-244

Rossmeisl M, Macek Jilkova Z, Kuda O, et al. (2012) Metabolic effects of n-3 PUFA as phospholipids are superior to triglycerides in mice fed a high-fat diet: Possible role of endocannabinoids, PLoS One 7: e38834

Ryckebosch E, Muylaert K, Foubert I (2012) Optimization of an analytical procedure for extraction of lipids from microalgae. J Am Oil Chem Soc 89:189-198

Ryckebosch E, Bermúdez SPC, Termote-Verhalle R, Bruneel C, Muylaert K, Parra-Saldivar R, Foubert I (2014a) Influence of extraction solvent system on the extractability of lipid components from the biomass of Nannochloropsis gaditana. J Appl Phycol 26:1501-1510

Ryckebosch E, Bruneel C, Termote-Verhalle R, Muylaert K, Foubert I (2014b) Influence of extraction solvent system on extractability of lipid components from different microalgae species. Algal Res 3:36-43

Sangster J (1989) Octanol-water partition coefficients of simple organic compounds. J Phys Chem Ref Data 18:111-1277

Servaes K, Maesen M, Prandi B, Elst KJ (2015) Polar lipid profile of Nannochloropsis oculata determined using a variety of lipid extraction procedures. J Agric Food Chem 63:3931-3941

Shahidi F, Wanasundara PKJPD (2002) Extraction and analysis of lipids. In: Akoh CC, Min DB (eds) Food lipids. Marcel Dekker, New York, pp 133-138

Swanson D, Block R, Mousa S (2012) Omega-3 fatty acids EPA and DHA: health benefits throughout life. Adv Nutr 3:1-7

Tang X, Li ZJ, Xu J, Xue Y, Li JZ, Wang JF, Yanagita T, Xue CH, Wang YM (2012) Short term effects of different omega-3 fatty acid formulation on lipid metabolism in mice fed high or low fat diet. Lipids Health Dis 11:70-78

van Hoogevest P, Wendel A (2014) The use of natural and synthetic phospholipids as pharmaceutical excipients. Eur J Lipid Sci Technol 116:1088-1107

Yoshitomi T, Mizoguchi T, Kunieda M, Tamiaki H (2011) Characterization of glycolipids in light-harvesting chlorosomes from the green photosynthetic bacterium Chlorobium tepidum. Bull Chem Soc Jpn 84:395-402

Authors' contributions All authors have contributed to the manuscript. All authors contributed to the research design, data analyses, and all of them revised, edited, and approved the final manuscript. The experimental work was carried out by María José Jiménez Callejón.

Publisher's note Springer Nature remains neutral with regard to jurisdictional claims in published maps and institutional affiliations. 